\title{
lonic liquid phase microextraction combined with fluorescence spectrometry for preconcentration and quantitation of carvedilol in pharmaceutical preparations and biological media
}

\author{
Mohsen Zeeb* and Behrooz Mirza
}

\begin{abstract}
Background: Carvedilol belongs to a group of medicines termed non-selective beta-adrenergic blocking agents. In the presented approach, a practical and environmentally friendly microextraction method based on the application of ionic liquids (ILS) was followed by fluorescence spectrometry for trace determination of carvedilol in pharmaceutical and biological media.

Methods: A rapid and simple ionic liquid phase microextraction was utilized for preconcentration and extraction of carvedilol. A hydrophobic ionic liquid (IL) was applied as a microextraction solvent. In order to disperse the IL through the aqueous media and extract the analyte of interest, IL was injected into the sample solution and a proper temperature was applied and then for aggregating the IL-phase, the sample was cooled in an ice water-bath. The aqueous media was centrifuged and IL-phase collected at the bottom of the test tube was introduced to the micro-cell of spectrofluorimeter, in order to determine the concentration of the enriched analyte.
\end{abstract}

Results: Main parameters affecting the accuracy and precision of the proposed approach were investigated and optimized values were obtained. A linear response range of $10-250 \mu \mathrm{g} \mathrm{I}^{-1}$ and a limit of detection (LOD) of $1.7 \mu \mathrm{g} \mathrm{I^{-1 }}$ were obtained.

Conclusion: Finally, the presented method was utilized for trace determination of carvedilol in commercial pharmaceutical preparations and biological media.

Keywords: Carvedilol, Hydrophobic ionic liquid, Spectrofluorimetry, Real samples

\section{Background}

Carvedilol belongs to a group of medicines termed nonselective beta-adrenergic blocking agents (Figure 1). This drug is useful in treatment of congestive heart failure. In addition, carvedilol is applied to treat high blood pressure (hypertension) and for prevention of heart attacks [1,2].

In order to assay the presence of carvedilol in pharmaceutical and biological samples, some analytical approaches including chromatography [3-6], spectrophotometery [7], electrochemistry $[8,9]$ and fluorimetry $[10]$ have been developed. These methods suffer form some limitations including poor sensitivity, high cost of analysis, unsuitable

\footnotetext{
* Correspondence: Zeeb.mohsen@gmail.com

Department of Applied Chemistry, Faculty of science, Islamic Azad University, South Tehran Branch, Tehran, Iran
}

selectivity and high time of analysis. One of the best choices for overcoming the mentioned problems is the combination of a practical sample enrichment method with analytical instruments.

In recent years, analytical chemists have developed some practical liquid phase microextraction methods and among these sample pretreatment methods, dispersive liquid-liquid microextraction (DLLME) has received much attention [11,12]. Unfortunately, one of the most important disadvantages of these microextraction methods is the usage of toxic solvents as the extraction solvent such as $\mathrm{CHCl}_{3}, \mathrm{CCl}_{4}$ and etc. In order to remove these toxic materials from microextraction procedures, ionic liquids (ILs) are the best choice. ILs offer many 


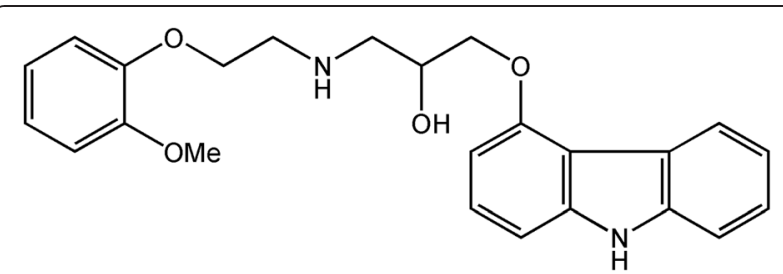

Figure 1 Structure of carvedilol.

advantages such as low vapor pressure, tunable solubility, desire thermal stability and etc. [13].

In recent years, some microextraction methods based on the application of ILs such as ionic liquid-based dispersive liquid-liquid microextraction (IL-DLLME) [14-16], ionic liquid cold-induced aggregation dispersive liquidliquid microextraction (IL-CIA-DLLME) [17-19], ionic Liquid-based ultrasound-assisted in situ solvent formation microextraction [20], temperature-controlled ionic liquid dispersive liquid phase microextraction (TCIL-DLPME) [21], etc. have been introduced.

Solubility of ILs depends on the aqueous media temperature; hence it is possible to control the solubility of ILs by changing the temperature. In the presented ionic liquid phase microextraction, in order to disperse the IL-phase into the sample solution and increase the extraction recovery, a high temperature was applied. For collecting the IL-phase, sample solution was cooled and centrifuged.

Our previous studies revealed that the solubility of ILs depends on ionic strength of aqueous media, which has a negative influence on reproducibility and accuracy $[18,19]$. For solving this problem, a common ion of IL was introduced to the aqueous media. As a result, the solubility of IL phase was not affected by variations of ionic strength, and reproducible volume of enriched phase was obtained.

Some analytical instrument such as spectrofluorimetry offer many advantages such as proper sensitivity, selectivity, cost of analysis, speed of quantitative measurements and etc. In addition, by coupling a microextraction method with fluorescence spectrometry and due to the proper selectivity of this analytical technique, it is avoided the need of employing a high performance separation instrumental for pretreatment of biological samples prior to measurement.

As a part of our continuing efforts for quantitation of drugs using combination of new and benign sample enrichment methods with inexpensive, selective and sensitive analytical instrument $[18,21]$, herein, for the first time a practical and environmentally friendly microextraction method based on the application of ILs was followed with spectrofluorimetry for trace determination of carvedilol in real samples. All variable were evaluated in details and optimized values were obtained.

\section{Material and methods} Instrumentation

Detection of fluorescence signals were performed using a Perkin-Elmer LS 50 spectrofluorimeter. This instrument was equipped with xenon discharge lamp, and quartz micro-cell with a volume of $100 \mu$ l. Excitation and emission slits were fixed at $15 \mathrm{~nm}$. In order to perform microextraction and optimization steps, a centrifuge from Hettich (Tuttlingen, Germany), a $\mathrm{pH}$-meter, an adjustable sampler $(10-100 \mu \mathrm{L})$ and a $1 \mathrm{ml}$ syringe was prepared.

\section{Reagents and materials}

Analytical-reagent grade of 1-Hexyl-3-methylimidazolium hexafluorophosphate $[\mathrm{Hmim}]\left[\mathrm{PF}_{6}\right]$, acetone, acetonitrile, methanol, ethanol, $\mathrm{HCl}, \mathrm{NaOH}$ and sodium hexafluorophosphate $\left(\mathrm{NaPF}_{6}\right)$ were obtained from Merck (Darmstadt, Germany). A working solution of $\mathrm{NaPF}_{6}\left(250 \mathrm{mg} \mathrm{ml}^{-1}\right)$ was prepared. For preparing stock solution of carvedilol (1000 $\mathrm{mg} \mathrm{l}^{-1}$ ) (Fluka, Switzerland), proper amount of this drug was dissolved in methanol and diluted with ultra pure water. Standard solutions were prepared by dilution of the stock solution with ultra pure water. Tablets containing $12.5 \mathrm{mg}$ and $25 \mathrm{mg}$ carvedilol were purchased from a local pharmacy.

\section{Sample pretreatment procedure}

In this sample pretreatment method, ten milliliters of sample solution (10-250 $\mu \mathrm{g} \mathrm{l}^{-1}$ of carvedilol) was transferred to a centrifuge tube. The $\mathrm{pH}$ of the solution was adjusted at 9. Afterwards, $60 \mathrm{mg}$ of 1-Hexyl-3-methylimidazolium hexafluorophosphate $[\mathrm{Hmim}]\left[\mathrm{PF}_{6}\right]$ ionic liquid and $0.7 \mathrm{ml}$ of hexafluorophosphate $\left(\mathrm{NaPF}_{6}\right) \quad\left(250 \mathrm{mg} \mathrm{ml}^{-1}\right)$ was injected into the aqueous sample solution. After mixing the extractor with sample solution, the resultant solution was transferred into a hot water batch equipped with a thermostat. The temperature of the water batch was fixed at $50^{\circ} \mathrm{C}$ for $4 \mathrm{~min}$. Under driving the temperature, ILphase was dissolved and dispersed through the aqueous media. In order to aggregate the IL-phase, the sample was cooled at $0^{\circ} \mathrm{C}$ for $7 \mathrm{~min}$. In order to collect the enriched phase, sample solution was centrifuged (6 min, 4000 r.p.m). After removing the aqueous media, the enriched phase was diluted with ethanol to $200 \mu \mathrm{l}$ and transferred into the micro-cell of the spectrofluorimeter. Finally, quantitation of carvedilol was performed. Schematic diagram of the designed method is shown in Figure 2.

Preparation of pharmaceutical preparations, human urine and human plasma

To obtain pharmaceutical solutions for quantification, eight carvedilol tablets containing 12.5 or $25 \mathrm{mg}$ drug were powdered, mixed and weighted. Required amount of the resultant material containing $10 \mathrm{mg}$ carvedilol 

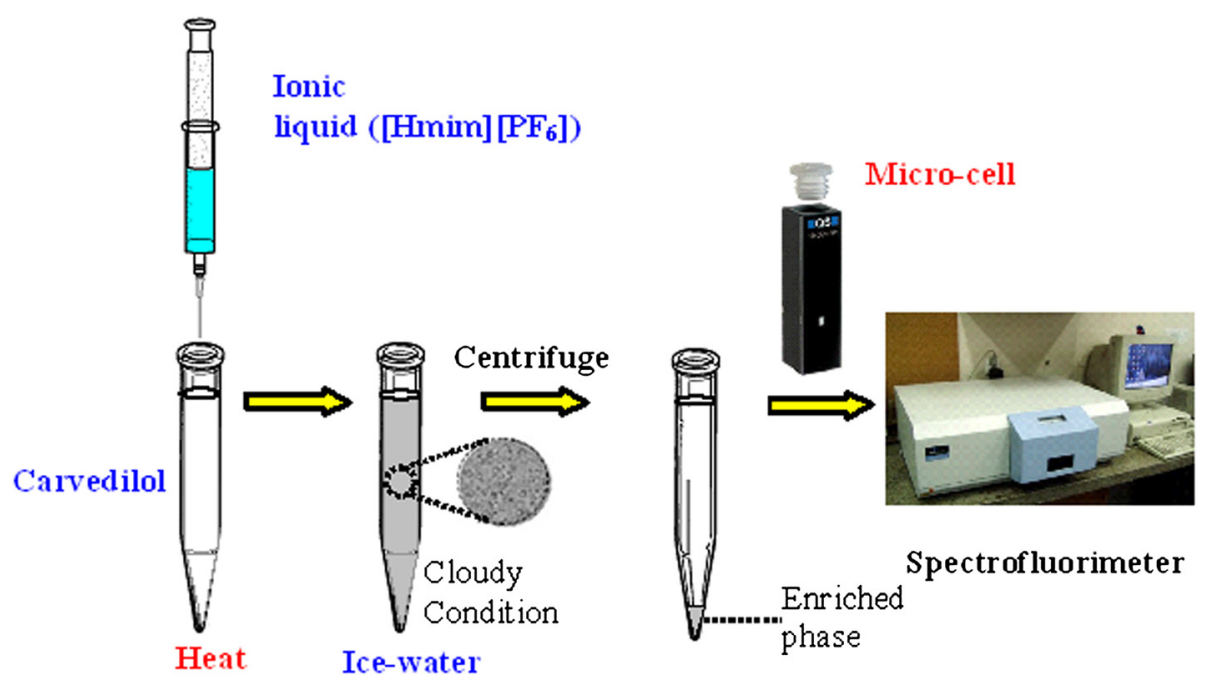

Figure $\mathbf{2}$ Schematic diagram of the proposed method.

was dissolved in methanol with signification. After filtration, the solution was transferred into a $100 \mathrm{ml}$ volumetric vessel and diluted with ultra pure water. In order to set the concentration of carvedilol within the linear response range, further dilution was performed.

For preparing human plasma samples, different concentrations of carvedilol were added to one milliliter of human plasma. After this step, the real sample was deproteinized using $5 \mathrm{ml}$ of acetonitrile. After centrifugation $(12 \mathrm{~min}$, 4000 r.p.m), $2.0 \mathrm{ml}$ of the upper phase (clear condition) was diluted with ultra pure water and $10.0 \mathrm{ml}$ of the obtained sample was utilized for quantitation.

In order to prepare human urine samples, ten milliliters of urine were centrifuged ( $5 \mathrm{~min}, 4000$ r.p.m). Then, $2.0 \mathrm{ml}$ of the upper clear phase was placed in centrifuge test tube and different amount of carvedilol was added to this and diluted to $10.0 \mathrm{ml}$. Finally, the defined quantitation procedure was performed.

\section{Results and discussion}

In recent work, a simple and benign sample pretreatment method based on the application of ILs was combined with fluorescence spectrometry for enrichment and determination carvedilol in real samples. Main parameters affecting the accuracy and precision of the proposed approach were investigated and optimized values were obtained.

Fluorescence spectra properties and linear dynamic range Native Fluorescence intensities of molecules with $\pi$ electron and cyclic structure are relatively high. As a result, measurement of fluorescence intensity provides a

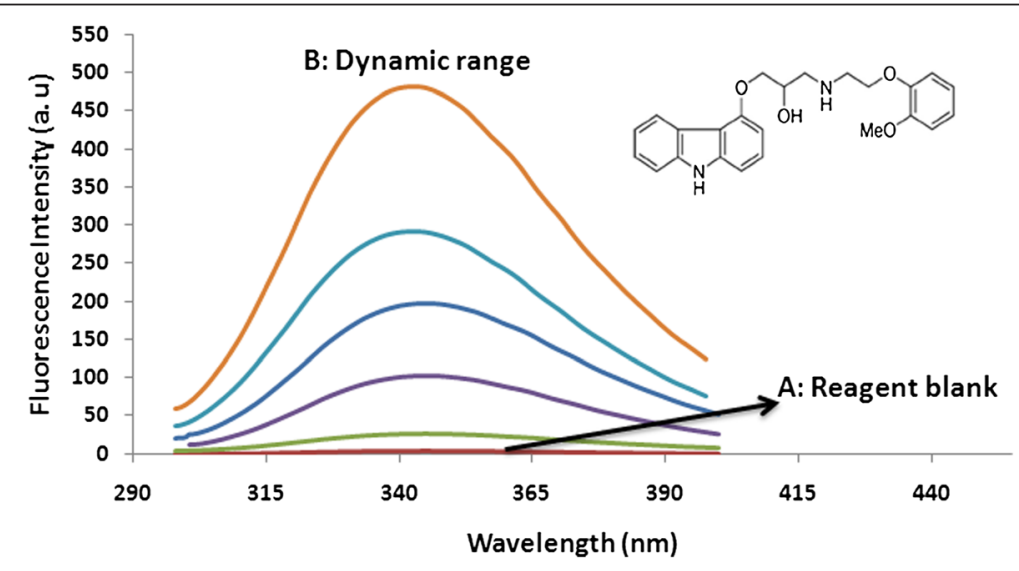

Figure 3 Fluorescence spectra of reagent blank and carvedilol. (A) Fluorescence spectrum of reagent blank after applying microextraction procedure. (B) Fluorescence spectra of carvedilol within linear dynamic range $\left(10,50,100,150,250 \mathrm{\mu g} \mathrm{I}^{-1}\right)$ after applying microextraction procedure. Applied parameters: sample volume $10 \mathrm{ml}$; IL $60 \mathrm{mg} ; \mathrm{NaPF}_{6} 175 \mathrm{mg}$; pH 9; temperature $50^{\circ} \mathrm{C} ; \lambda_{\text {ex }} 285 \pm 5 \mathrm{~nm} ; \lambda_{\text {em }} 345 \pm 5 \mathrm{~nm}$. 
practical tool for sensitive quantitative analysis. After applying the designed microextraction procedure, fluorescence spectra of carvedilol $\left(100 \mu \mathrm{g} \mathrm{l}^{-1}\right)$ was recorded (Figure 3). In this study, emission peaks were recorded at $345 \pm 5 \mathrm{~nm}$ (excitation wave length was fixed at $285 \pm 5 \mathrm{~nm}$ ).

In order to evaluate the spectra properties of reagent blank, sample pretreatment method was performed without analyte of interest and the fluorescence spectra were recorded at $345 \pm 5 \mathrm{~nm}$. No main measurable influence of reagent blank on the quantitative analysis of carvedilol was observed. As a result, these excitation and emission wavelengths were selected for further quantitation of carvedilol.

\section{Kind of ionic liquid}

Based on the results obtained in our previous studies $[18,19]$, three factors must be considered, in order to select a proper IL: (a) the density of IL as the extraction solvent must be higher than aqueous media, (b) IL must illustrate a desire hydrophobicity, (c) IL must be liquid and (d) these ionic material must be inexpensive. ILs with imidazolium scaffold which contain $\mathrm{Cl}^{-}, \mathrm{BF}_{4}{ }^{-}$and $\mathrm{CF}_{3} \mathrm{SO}_{3}{ }^{-}$show hydrophilic properties and those contain $\mathrm{PF}_{6}{ }^{-}$and $\left(\mathrm{CF}_{3} \mathrm{SO}_{2}\right)_{2} \mathrm{~N}^{-}$show hydrophobic properties.

According to these factors, $[\mathrm{Hmim}]\left[\mathrm{PF}_{6}\right]$ was used as an optimum microextraction solvent in all tests.

\section{Optimization of diluting solvent}

The viscosity of ionic liquids is relatively high; hence their direct transfer into the micro-cell of spectrofluorimeter for analyzing carvedilol is difficult. As a result, enrichedphase was conditioned and diluted. For this goal, some conditioner solvents such as methanol, ethanol, acetonitrile and acetone were evaluated as the diluting solvent. The obtained data showed that reproducible and sensitive

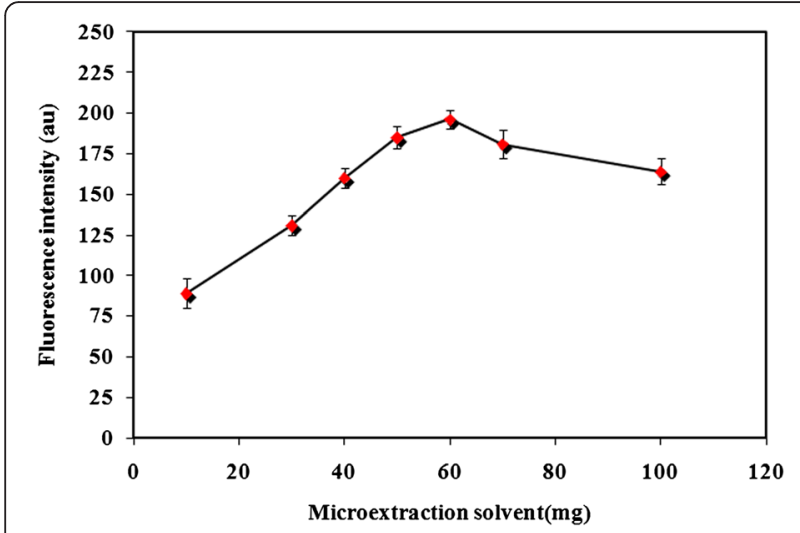

Figure 4 Effect of IL as the microextraction phase. Applied parameters: Carvedilol concentration $100 \mu \mathrm{gl}^{-1}$; sample volume $10 \mathrm{ml}$; $\mathrm{NaPF}_{6}$ $175 \mathrm{mg} ; \mathrm{pH}$ 9; temperature $50^{\circ} \mathrm{C} ; \lambda_{\text {ex }} 285 \pm 5 \mathrm{~nm} ; \lambda_{\mathrm{em}} 345 \pm 5 \mathrm{~nm}$. Indicated analytical signals are the average of three independent measurements and error bars correspond to their standard deviations.

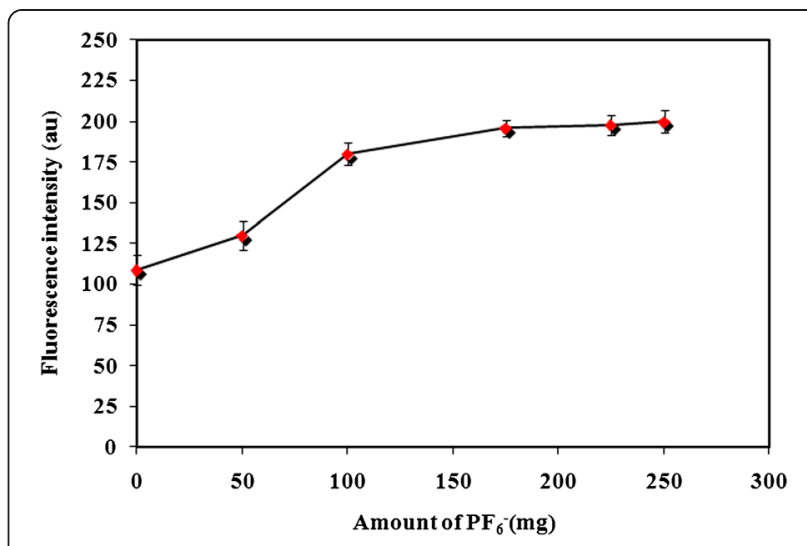

Figure $\mathbf{5}$ Effect of $\mathrm{PF}_{6}{ }^{-}$Applied parameters: Carvedilol concentration $100 \mathrm{\mu g} \mathrm{I}^{-1}$; Sample volume $10 \mathrm{ml}$; IL $60 \mathrm{mg}$; pH 9; temperature $50^{\circ} \mathrm{C}$; $\lambda_{\text {ex }} 285 \pm 5 \mathrm{~nm} ; \lambda_{\text {em }} 345 \pm 5 \mathrm{~nm}$. Indicated analytical signals are the average of three independent measurements and error bars correspond to their standard deviations.

signals were obtained in using ethanol as a conditioner agent. Due to the better data stability and ethanol environmental safety (less toxicity), this organic solvent was preferred and used in all experiments.

\section{Optimization of IL amount}

As it was mentioned, in this microextraction procedure, IL was applied as the microextraction phase. In this kind of sample pretreatment method, one of the major parameters affecting the performance is the amount of IL. This parameter has a significant effect on the reproducibility and sensitivity. In order to optimize the amount of extraction solvent, this parameter was tested within the range of 10-100 mg (Figure 4). Stable and sensitive fluorescence signals were obtained at $60 \mathrm{mg}$ and this value was used for the rest of the work.

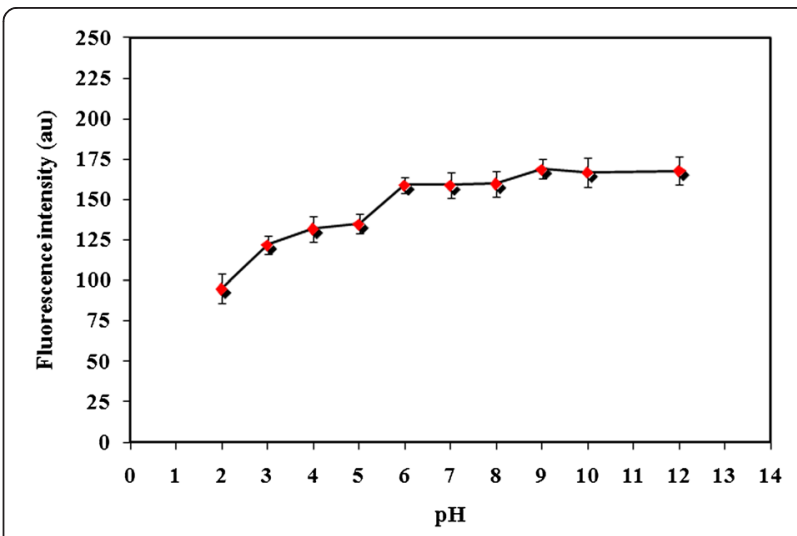

Figure 6 Effect of $\mathrm{pH}$. Applied parameters: Carvedilol concentration $100 \mathrm{\mu g} \mathrm{I}^{-1}$; sample volume $10 \mathrm{ml}$; IL 60 mg; NaPF 175 mg; temperature $50^{\circ} \mathrm{C} ; \lambda_{\text {ex }} 285 \pm 5 \mathrm{~nm}$; $\lambda_{\text {em }} 345 \pm 5 \mathrm{~nm}$. Indicated analytical signals are the average of three independent measurements and error bars correspond to their standard deviations. 
Table 1 Analytical characteristics of the presented work

\begin{tabular}{|c|c|}
\hline Analytical factor & Values \\
\hline Linear analytical response range $\left(\mu \mathrm{g} \mathrm{I}^{-1}\right)$ & $10-250$ \\
\hline Correlation coefficient $\left(R^{2}\right)$ & 0.9980 \\
\hline $\operatorname{LOD}^{a}\left(\mu \mathrm{g} \mathrm{I}^{-1}\right)$ & 1.7 \\
\hline $\operatorname{RSD}^{\mathrm{b}}(\%)(\mathrm{n}=4)\left(\mathrm{C}_{\text {carvedilol }}=100 \mu \mathrm{gl}^{-1}\right)$ & 3.8 \\
\hline $\mathrm{PF}^{\mathrm{C}}$ & 50 \\
\hline Sample volume (mL) & 10 \\
\hline
\end{tabular}

\section{Optimization of $\mathrm{PF}_{6}{ }^{-}$amount and ionic strength}

As it was demonstrated in our previous works $[18,19]$, dissolving a common ion of IL like $\mathrm{PF}_{6}{ }^{-}$, significantly reduce the solubility of IL. This act improves the extraction performance of carvedilol and provides better analytical sensitivity. Effect of this parameter was examined in the range of $0-250 \mathrm{mg}$ (see Figure 5). A value of $175 \mathrm{mg}$ was selected as an optimum value, in order to obtain proper signal stability and reproducibility.

One of the most important parameters which affects on the extraction performance is ionic strength of the aqueous media. An increase in ionic strength causes a considerable increase in solubility of IL. As a result, the volume of the settled phase depends on the salt content of the sample solution. This phenomenon has a negative influence on the stability of analytical data. Fortunately, presence of $\mathrm{PF}_{6}^{-}$(as a common ion) solves this problem and fixes the volume of the enrich phase. The effect of ionic strength was studied within the range of $0-40 \%$ (w/v) using $\mathrm{NaNO}_{3}$ as an electrolyte. In the studied range, no significant influence on fluorescence signal was observed.

Table 2 Comparison of the proposed methodology with reported methods

\begin{tabular}{|c|c|c|c|c|}
\hline Method & Sample & $\begin{array}{l}\text { LOD } \\
\left(\mu \mathrm{g} \mathrm{I}^{-1}\right)\end{array}$ & $\operatorname{LR}\left(\mu \mathrm{g} \mathrm{I}^{-1}\right)$ & Reference \\
\hline$\overline{D L L M E-H P L C}{ }^{a}$ & $\begin{array}{l}\text { Human Urine, } \\
\text { Human Plasma }\end{array}$ & 4,14 & $\begin{array}{l}\text { 50-750 } \\
20-1000\end{array}$ & {$[6]$} \\
\hline SPE-CE ${ }^{b}$ & Human Urine & 50 & $50-500$ & [23] \\
\hline $\begin{array}{l}\text { Synchronous } \\
\text { fluorimetry }\end{array}$ & $\begin{array}{l}\text { Pharmaceutical } \\
\text { preparations }\end{array}$ & 1 & $5-100$ & {$[24]$} \\
\hline LLE-HPLC ${ }^{c}$ & Human serum & 2.5 & $5-500$ & {$[25]$} \\
\hline $\begin{array}{l}\text { Ionic liquid phase } \\
\text { microextraction- } \\
\text { spectrofluorimetry }\end{array}$ & $\begin{array}{l}\text { Human Urine, } \\
\text { Human Plasma, } \\
\text { Pharmaceutical } \\
\text { preparations }\end{array}$ & 1.7 & $10-250$ & This work \\
\hline
\end{tabular}

${ }^{\mathrm{a}}$ Dispersive liquid-liquid microextraction.

${ }^{\text {b}}$ Solid phase extraction-capillary electrophoresis.

'Liquid-liquid extraction.
Table 3 Results of recoveries of spiked biological samples

\begin{tabular}{|c|c|c|c|c|}
\hline Sample & $\begin{array}{l}\text { Carvedilol } \\
\text { added }\left(\mu \mathrm{g} \mathrm{I}^{-1}\right)\end{array}$ & $\begin{array}{l}\text { Carvedilol } \\
\text { found }\left(\mu \mathrm{g} \mathrm{I}^{-1}\right)^{\mathrm{a}}\end{array}$ & RSD (\%) & Recovery (\%) \\
\hline \multirow[t]{3}{*}{ Urine } & 50 & 53.2 & 6.1 & 106.4 \\
\hline & 100 & 98.3 & 5.9 & 98.3 \\
\hline & 150 & 146.1 & 3.8 & 97.4 \\
\hline \multirow[t]{3}{*}{ Plasma } & 50 & 44.6 & 5.6 & 89.2 \\
\hline & 100 & 107.3 & 7.1 & 107.3 \\
\hline & 150 & 154.8 & 4.2 & 103.2 \\
\hline
\end{tabular}

${ }^{\mathrm{a}}$ Average of four independent measurements.

\section{Optimization of $\mathrm{pH}$}

In the case of microextraction of molecules like carvedilol, which have ionizable property, $\mathrm{pH}$ of the aqueous media reveals a significant role. In order to obtain the highest extraction efficiency, the uncharged condition of carvedilol must be prevalent $\left(\mathrm{pK}_{\mathrm{a}}\right.$ value of carvedilol is 7.97) [22]. The effect of sample $\mathrm{pH}$ on the analytical sensitivity and reproducibility was tested within the range of 2-12 (Figure 6). In the recent experiments, $\mathrm{HCl}$ and $\mathrm{NaOH}$ were used for adjusting the $\mathrm{pH}$. Based on the results obtained in this study, in order to obtain a compromise between sensitivity and reproducibility, $\mathrm{pH} 9$ was selected for further experiments.

\section{Influence of temperature}

In this microextraction procedure, IL-phase is dispersed into the aqueous media under increasing the temperature. The effect of this parameter was evaluated in the range of $25-80^{\circ} \mathrm{C}$. Finally, a temperature of $50^{\circ} \mathrm{C}$ was used as an optimum value. In order to collect the IL-phase after extraction, the sample solution must be cooled. For the recent goal, the aqueous media was placed in ice-water bath and kept at $0^{\circ} \mathrm{C}$ for $7 \mathrm{~min}$.

\section{Interference study}

For studying the possible interferences coming form other compounds, which exist in real samples, some ions and compounds were subjected to the recent combined methodology. In this investigation, the effect of 100-fold of $\mathrm{K}^{+}, \mathrm{Na}^{+}, \mathrm{Mg}^{+}, \mathrm{F}^{-}, \mathrm{Cl}^{-}, \mathrm{NO}_{3}{ }^{-}, \mathrm{SO}_{4}{ }^{2-}$, glucose, urea, lactic acid, sucrose, ascorbic acid and fructose as the interfering or quenching agents on the determination of

Table 4 Analysis of carvedilol tablets by the present work and the reported method (5)

\begin{tabular}{|c|c|c|c|c|}
\hline $\begin{array}{l}\text { Claimed } \\
\text { (mg/tablet) }\end{array}$ & $\begin{array}{l}\text { Proposed } \\
\text { method }(\mathrm{mg})^{\mathrm{a}}\end{array}$ & $\begin{array}{l}\text { Reported } \\
\text { method }(\mathrm{mg})^{\mathrm{a}}\end{array}$ & Error (\%) & Error (\%) \\
\hline 12.5 & $12.3( \pm 0.5)$ & $12.6( \pm 0.4)$ & -1.6 & -2.9 \\
\hline 25 & $25.5( \pm 1.0)$ & $25.7( \pm 1.1)$ & +2.0 & -0.7 \\
\hline
\end{tabular}

${ }^{2}$ Values in parenthesis give the standard deviation based on four determinations. ${ }^{\mathrm{b}}$ Error against the tablet value.

${ }^{\mathrm{C}}$ Error against the reported method. 
carvedilol $\left(100 \mu \mathrm{g} \mathrm{L}^{-1}\right)$ was evaluated. No change in signals over than $4.5 \%$ was observed.

\section{Analytical figures of merits}

Linear analytical response range was defined by analyzing standard solutions of carvedilol. The obtained results revealed that analytical responses are linear from 10 to $250 \mu \mathrm{g} \mathrm{l}^{-1}$. Other analytical figures of merits obtained by the ionic liquid phase microextraction-spectrofluorimetry are shown in Table 1. Limit of detection (LOD) was determined using a conventional equation, $\mathrm{LOD}=\mathrm{ks}_{\mathrm{bl}} / \mathrm{m}$. This equation is resulted from the equation showed below:

$$
\begin{aligned}
& S_{m}=S_{b l}+k s_{b l} \\
& S_{m}=m c_{m}+S_{b l} \\
& c_{m}=\frac{S_{m}-S_{b l}}{m}=\frac{k s_{b l}}{m}
\end{aligned}
$$

$\mathrm{S}_{\mathrm{m}}, \mathrm{S}_{\mathrm{bl}}, \mathrm{s}_{\mathrm{bl}}, \mathrm{K}, \mathrm{m}$ and $\mathrm{C}_{\mathrm{m}}$ show the minimum distinguishable analytical signal, average of blank analytical signal, blank standard deviation, constant value equal with 3 (confidence level of 95\%), calibration graph slope and detection limit, respectively. Using this way, a value of $1.7 \mu \mathrm{g} \mathrm{l}^{-1}$ carvedilol was achieved. In order to determine the relative standard deviation (RSD), four $100 \mu \mathrm{g} \mathrm{l}^{-1}$ of carvedilol was subjected to the designed methodology and finally a value of $3.8 \%$ was obtained.

\section{Comparison with reported methods}

In order to show the analytical advantages of the proposed method for the quantitation of carvedilol, some details were compared with reported methods in literature, and these results are shown in Table 2. As it can be seen, considerable LOD and relatively wide dynamic range were obtained. In addition, in most of the reported methods, tedious sample pretreatment procedures, toxic solvents and expensive analytical instrument have been used for quantification. In contrast, in the proposed method, a rapid, benign and simple ionic liquid phase microextraction was utilized for preconcentration and extraction of carvedilol. No hazardous material was used in this sample pre-treatment method. In addition, an inexpensive and sensitive analytical instrument was applied for quantitation.

\section{Analysis of carvedilol in real samples}

In order to demonstrate the analytical application of the presented technique, real samples including human urine and human plasma were spiked with different amounts of carvedilol and analyzed. Results of this investigation are shown in Table 3 . At it can be seen, the averages of recoveries are placed in the range of 97.4$106.2 \%$ (urine) and $89.2-107.3 \%$ (plasma). It can be concluded that in the case of accuracy and reproducibility, satisfactory results were obtained. In the next step, some commercial pharmaceutical formulations involving carvedilol capsules and tablets were subjected to the designed method, in order to determine concentration of carvedilol (Table 4). The results obtained with the present work were compared with a reported method [5]. These data reveal the practical analytical application of the proposed method for analyzing the analyte of interest in pharmaceutical preparations.

\section{Conclusion}

A rapid, benign and simple ionic liquid phase microextraction was utilized for preconcentration and extraction of carvedilol. The enriched-phase was introduced to spectrofluorimeter for quantitation of carvedilol. No toxic and hazardous material was used in this sample pre-treatment method. In addition, an inexpensive and sensitive analytical instrument was applied for quantitative measurements. Finally, the combined methodology was successfully applied for quantitation of carvedilol in real samples.

\section{Competing interests}

The authors declare that they have no competing interests.

Authors' contributions

All authors contributed equally. Both authors read and approved the final manuscript.

\section{Acknowledgment}

Support of this investigation by the Islamic Azad University Tehran south branch through grant is gratefully acknowledged.

Received: 6 January 2015 Accepted: 20 April 2015

Published online: 30 April 2015

\section{References}

1. Packer M, Colicci WS, Sacker-Bernstein JD. Placebo-controlled study of the effects of carvedilol in patients with moderate to severe heart failure, the PRECISE trial. Circulation. 1996;94:2793-9.

2. Bristow MR, Gilbert EM, Abraham WT, Adams KF, Fowler MB, Hershberger RE, et al. Carvedilol produces dose related improvements in left ventricular function and survival in subjects with chronic heart failure. Circulation. 1996:94:2807-16.

3. Hokama N, Hobara N, Kameya H, Ohshiro S, Sakanashi M. Rapid and simple micro-determination of carvedilol in rat plasma by high performance liquid chromatography. J Chromatogr, B. 1999;732:233-8.

4. Machida M, Watanabe M, Takechi S, Kakinoki S, Nomura A. Measurement of carvedilol in plasma by high-performance liquid chromatography with electrochemical detection. J Chromatogr, B. 2003;798:187-91.

5. Zarghi A, Foroutan SM, Shafaati A, Khoddam A. Quantification of carvedilol in human plasma by liquid chromatography using fluorescence detection: application in pharmacokinetic studies. J Pharm Biomed Anal. 2007:44:250-3.

6. Zamani-Kalajahi M, Fazeli-Bakhtiyari R, Amiri M, Golmohammadi A, Afrasiabi A, Khoubnasabjafari M, et al. Analysis of losartan and carvedilol in urine and plasma samples using a dispersive liquid-liquid microextraction isocratic HPLC-UV method. Bioanalysis. 2012;4:2805-21.

7. Cardoso SG, leqqli CV, Pomblum SC. Spectrophotometric determination of carvedilol in pharmaceutical formulations through charge-transfer and ion-pair complexation reactions. Pharmazie. 2007;62:34-7.

8. Radi A, Elmogy T. Differential pulse voltammetric determination of carvedilol in tablets dosage form using glassy carbon electrode. II Farmaco. 2005;60:43-6. 
9. Soleymanpour A, Ghasemian M. Chemically modified carbon paste sensor for the potentiometric determination of carvedilol in pharmaceutical and biological media. Measurement. 2015;59:14-20.

10. Silva RA, Wang CC, Fernandez LP, Masi AN. Flow injection spectrofluorimetric determination of carvedilol mediated by micelles. Talanta. 2008;76:166-71.

11. Zeeb M, Ganjali MR, Norouzi P. Dispersive liquid-liquid microextraction followed by spectrofluorimetry as a simple and accurate technique for determination of thiamine (vitamin $B_{1}$ ). Michrochim Acta. 2010;168:317-24.

12. Bidari A, Jahromi EZ, Assadi $Y$, Hosseini MRM. Monitoring of selenium in water samples using dispersive liquid-liquid microextraction followed by iridium-modified tube graphite furnace atomic absorption spectrometry. Microchem J. 2007;87:6-12

13. Zeeb M, Ganjali MR, Norouzi P, Kalaei MR. Separation and preconcentration system based on microextraction with ionic liquid for determination of copper in water and food samples by stopped-flow injection spectrofluorimetry. Food Chem Toxicol. 2011:49:1086-91.

14. Yao C, Anderson JL. Dispersive liquid-liquid microextraction using an in situ metathesis reaction to form an ionic liquid extraction phase for the preconcentration of aromatic compounds from water. Anal Bioanal Chem. 2009:395:1491-502

15. Yao C, Li T, Wu P, Pitner WR, Anderson JL. Selective extraction of emerging contaminants from water samples by dispersive liquid-liquid microextraction using functionalized ionic liquids. J Chromatogr A. 2011;1218:1556-66.

16. Gharehbaghi M, Shemirani F, Baghdadi M. Dispersive liquid-liquid microextraction based on ionic liquid and spectrophotometric determination of mercury in water samples. Int J Environ Anal Chem. 2009;89:21-33.

17. Zeeb M, Sadeghi M. Modified ionic liquid cold-induced aggregation dispersive liquid-liquid microextraction followed by atomic absorption spectrometry for trace determination of zinc in water and food samples. Microchim Acta. 2011;175:159-65.

18. Zeeb M, Ganjali MR, Norouzi P. Modified ionic liquid cold-induced aggregation dispersive liquid-liquid microextraction combined with spectrofluorimetry for trace determination of ofloxacin in pharmaceutical and biological samples. Daru. 2011;19:446-54.

19. Zeeb M, Ganjali MR, Norouzi P. Preconcentration and Trace Determination of Chromium Using Modified lonic Liquid Cold-Induced Aggregation Dispersive Liquid-Liquid Microextraction: Application to Different Water and Food Samples. Food Anal Method. 2013;6:1398-406.

20. Zeeb M, Mirza B, Zare-Dorabei R, Farahani H. lonic Liquid-based UltrasoundAssisted In Situ Solvent Formation Microextraction Combined with Electrothermal Atomic Absorption Spectrometry as a Practical Method for Preconcentration and Trace Determination of Vanadium in Water and Food Samples. Food Anal Method. 2014;7:1783-90.

21. Zeeb M, Tayebi-Jamil P, Berenjian A, Ganjali MR, Talei BOMR. Quantitative analysis of piroxicam using temperature controlled ionic liquid dispersive liquid phase microextraction followed by stopped-flow injection spectrofluorimetry. Daru. 2013:6:1398-406.

22. Stojanovic J, Vladimirov S, Marinkovic V, Velickovic D, Sibinovic $P$. Monitoring of the photochemical stability of carvedilol and its degradation products by the RP-HPLC method. J Serb Chem Soc. 2007;72:37-44.

23. Mazzarino M, De La Torre X, Mazzei F, Botre F. Rapid screening of beta-adrenergic agents and related compounds in human urine for anti-doping purpose using capillary electrophoresis with dynamic coating. J Sep Sci. 2009;32:3562-70.

24. Xiao Y, Wang HU, Han J. Simultaneous determination of carvedilol and ampicillin sodium by synchronous fluorimetry. Spectrochim Acta, Part A. 2005:61:567-73.

25. Gannu R, Yamsani W, Rao YM. New RP-HPLC method with UV-detection for the determination of carvedilol in human serum. J Liq Chromatogr Rel Technol. 2007;30:1677-85.

\section{Submit your next manuscript to BioMed Central and take full advantage of:}

- Convenient online submission

- Thorough peer review

- No space constraints or color figure charges

- Immediate publication on acceptance

- Inclusion in PubMed, CAS, Scopus and Google Scholar

- Research which is freely available for redistribution

Submit your manuscript at www.biomedcentral.com/submit 